\title{
OSTI
}

\section{CAPABILITIES OF THE DOE REMOTE SENSING LABORATORY'S AERIAL MEASURING SYSTEM}




\section{DISCLAIMER}

This report was prepared as an account of work sponsored by an agency of the United States Government. Neither the United States Government nor any agency thereof, nor any of their employees, makes any warranty, express or implied, or assumes any legal liability or responsibility for the accuracy, completeness, or usefulness of any information, apparatus, product, or process disclosed, or represents that its use would not infringe privately owned rights. Reference herein to any specific commercial product, process, or service by trade name, trademark, manufacturer, or otherwise, does not necessarily constitute or imply its endorsement, recommendation, or favoring by the United States Government or any agency thereof. The views and opinions of authors expressed herein do not necessarily state or reflect those of the United States Government or any agency thereof.

This report has been reproduced directly from the best available copy.

Available to DOE and DOE contractors from the Office of Scientific and Technical Information, P.O. Box 62, Oak Ridge, Tennessee 37831 ; prices available from (615) 576-8401.

Available to the public from the National Technical Information Service, U.S. Department of Commerce, 5285 Port Royal, Springfield, Virginia 22161. 


\section{CAPABILITIES OF THE DOE REMOTE SENSING LABORATORY'S AERIAL MEASURING SYSTEM}

S. R. Riedhauser

Project Scientist

\section{REVIEWED BY}

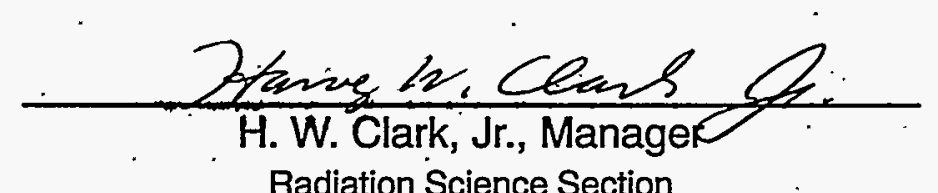

Radiation Science Section

This Document is UNCLASSIFIED

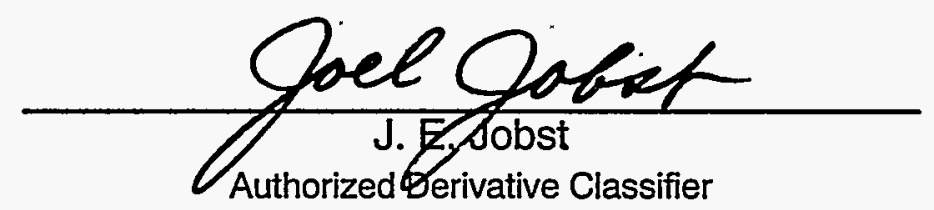

This work was performed by EG\&G/EM for the United States Department of Energy under Contract Number DE-AC08-93NV11265. 


\begin{abstract}
This report describes the capabilities of the Remote Sensing Laboratory's aircraft for use in environmental radiation surveys, multispectral (visible, near infrared, and thermal infrared) surveys of vegetation and buildings, and photographic documentation of the areas covered by the two other surveys. The report discusses the technical capabilities of the various systems and presents examples of the data from a recent demonstration survey.

To provide a view of the types of surveys the Remote Sensing Laboratory has conducted in the past, the appendices describe several of the previous area surveys and emergency search surveys.
\end{abstract}




\section{Contents}

Page

Abstract

\section{Sections}

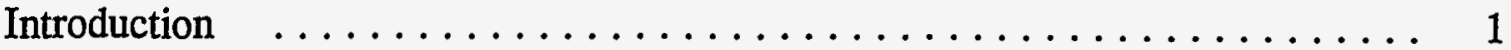

General Gamma Radiation Capabilities $\ldots \ldots \ldots \ldots \ldots \ldots \ldots \ldots \ldots \ldots \ldots$

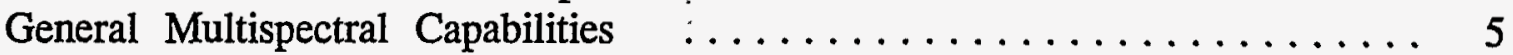

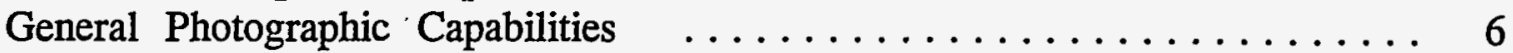

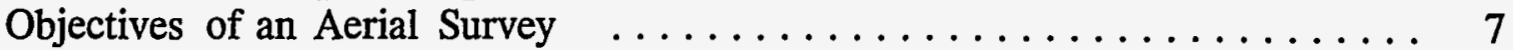

Results from a Demonstration Survey $\ldots \ldots \ldots \ldots \ldots \ldots \ldots \ldots$

\section{Appendices}

A Previous Gamma Radiation Surveys $\ldots \ldots \ldots \ldots \ldots \ldots \ldots \ldots \ldots$

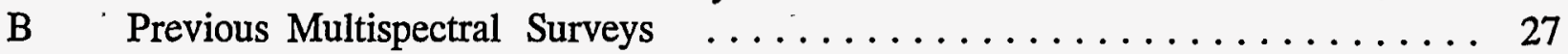

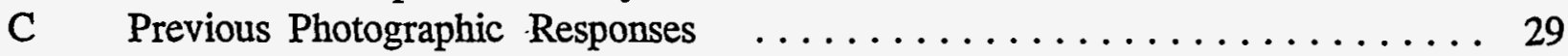

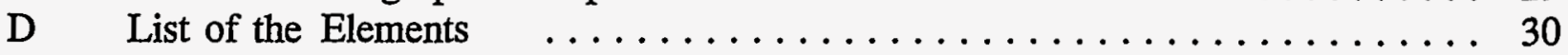

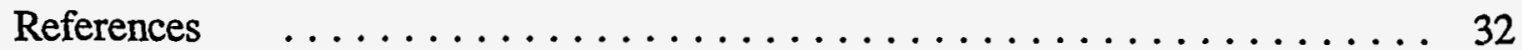

\section{List of Figures}

1 Photographic Image at 1,000-Foot Altitude (Indian Springs, Nevada) $\ldots \ldots 12$

2 Photographic Image at 2,500-Foot Altitude (Indian Springs, Nevada) $\ldots \ldots 13$

3 Photographic Image at 5,000-Foot Altitude (Indian Springs, Nevada) $\ldots . .14$

4 Photographic Image at 10,000-Foot Altitude (Indian Springs, Nevada) . . . 15

5 Multispectral Imaging Data at Four Altitudes (Indian Springs, Nevada) . . . 16

6 Multispectral Imaging Data at 5,000-Foot Altitude (Drainage Area) $\ldots . . .17$

7 Radiation Data at 300-Foot Altitude (Full Highway Route) . . . . . . . . 18

8 Gross Count Data at 300-Foot Altitude (Region of Source Canister) . . . . 19

9 Man-Made Data at 300-Foot Altitude (Region of Source Canister) . . . . 20

10 Man-Made Data at 500-Foot Altitude (Region of Source Canister) $\ldots . . .21$

\section{List of Tables}

1 Photographic field of view and resolution at four altitudes 


\section{WIPP Route Surveying Capabilities of the \\ DOE Remote Sensing Laboratory's \\ Aerial Measuring System}

Prepared by

S. R. Riedhauser

\section{Introduction}

The United States Department of Energy (DOE) maintains the Remote Sensing Laboratory (RSL), which supports several sensing programs. The three aerial capabilities (radiation, photographic, and multispectral imaging) discussed in this report comprise the Aerial Measuring System deployed by the RSL. The RSL is currently operated by EG\&G Energy Measurements, Inc. (EG\&G/EM), under contract to the DOE. The laboratory has major facilities in Las Vegas, Nevada; Washington, D.C.; and Santa Barbara, California.

As early as 1948 , aerial radiation measurements ${ }^{1}$ were made in the United States to determine the feasibility of airborne prospecting for deposits of radioactive ore. For different reasons, the U.S. Geological Survey and Oak Ridge National Laboratory developed several airborne radiation detecting systems in the mid1950s. These reasons included the Windscale nuclear reactor accident in the United Kingdom, the emergence of the commercial nuclear power reactors in the United States which would need large amounts of uranium for their operation, and the release of radioactive clouds from nuclear weapons tests in Nevada and the mid-Pacific.

The U.S. Atomic Energy Commission (a predecessor of the DOE) began a program in 1958 to map the terrestrial gamma radiation environment in and around facilities which produce, use, or store radioactive materials. As part of this ongoing program, the RSL routinely conducts aerial surveys for the DOE, the Nuclear Regulatory Commission (NRC), and other government agencies. These surveys use sodium-iodide ( $\mathrm{NaI}$ ) detectors to record the radiation energy spectrum during each second of flight. In addition to the aerial surveys, RSL scientists have conducted numerous ground-based surveys with high-purity germanium (HPGe) detectors to map the quantity and distribution of a specific isotope.

The aerial radiation surveys provide data which assist in effective environmental management at nuclear facilities. These surveys, if performed at the appropriate 
times, can also provide information on the radiation profile before, during, and after a facility is operating with radioactive materials.

The photographic program began around the same time as the radiation program and has principally provided photographic documentation of the changes in land use over a period of time. As particular DOE sites have grown, their impact on the surrounding landscape is recorded on film and the site's evolution can be assembled into a time-history of the area.

Optical scanning capabilities were initiated by the RSL in 1977 . The Daedalus multispectral scanners used. are sensitive to visible, reflective infrared, and thermal infrared energy. These spectral bands can be used for a variety of environmental survey purposes, including hydrologic surveys (e.g., groundwater seeps, water body temperatures, and flow patterns), surficial geology and soils assessments, land cover and use, and vegetation mapping (including vegetation type, amounts, and condition, especially stress).

The following sections discuss the capabilities of the different RSL groups in regard to surveying the designated highway routes to the Waste Isolation Pilot Project (WIPP) near Carlsbad, New Mexico. Following the discussion of capabilities, the last section discusses a recent demonstration survey by the three groups along the highway between Las Vegas and the Nevada Test Site. The figures in this report are designed principally to present and describe the data and do not reflect the data storage method proposed elsewhere for this project.

The appendices present brief synopses of some recent work similar to a response to a transportation accident. In particular, the radiation department has been involved in quite a number of "emergency" responses to locate lost radioactive sources, to map fields of dispersed radioactive contamination, or to track plumes of radioactive gases in the atmosphere. The multispectral group has detected and mapped vegetation stress due to hazardous. materials and thermal discharges, located groundwater seepages, and tracked thermal discharges into streams and rivers at nuclear facilities. The photographic department has used their equipment to record changes in the landscape over many years.

\section{General Gamma Radiation Capabilities}

One of the most widely known activities of the RSL is the mapping of gamma-ray emitting radionuclides from airborne platforms. ${ }^{2,3}$ Environmental monitoring of DOE and NRC facilities is the most common reason for these surveys, although the surveys are sometimes conducted to track radioactive gas releases, to search for lost radiation sources, or to search for disposal sites containing radioactive wastes mixed with other materials. 


\section{Aerial Measuring System}

A typical survey consists of flying an airplane or helicopter, equipped with several sodium-iodide $(\mathrm{NaI})$ detectors, at a constant altitude above the ground in a series of uniformly spaced flight lines. For a survey along a highway, the path could follow the twists and turns in the road,but would probably be broken into several distinct, abutting flight lines for reasons of computational ease.

A navigational system called the Real-time Differential Global Positioning System (RDGPS) on board the aircraft determines its position each second by receiving signals from the GPS satellites. Every four seconds, a GPS Base Station (programmed with the precise coordinates for its true position) also determines its position from the available satellites and broadcasts a positional correction to the aircraft. The correction term adjusts the aircraft's position, minimizing the errors incurred when using only the satellites to determine its position. A radar altimeter system continuously monitors and provides feedback to the pilot of the helicopter's altitude.

The detectors are carried inside the body of the airplane (for a long-distance highway survey) or in specially constructed "detector pods" mounted to the skid struts under the helicopter's body (for a typical AMS survey over a small area). The number of detectors carried inside the airplane varies depending on the sensitivity needed and how high the aircraft will be flying. For the helicopter, generally the two detector pods each carry four 2-in x 4-in x 16-in rectangular, thallium-activated sodium iodide, $\mathrm{NaI}(\mathrm{Tl})$, gamma-ray detectors plus a single 2 -in $\mathrm{x}$ 4-in $\mathrm{x}$ 4-in rectangular $\mathrm{NaI}(\mathrm{Tl})$ gamma-ray detector. The eight large, rectangular detectors view the total radiation field available to the helicopter. The smaller detectors provide a continuous monitor of the airborne radon and cosmic ray contribution to the radiation field.

The signals from the individual detectors, matched in amplitude and combined with summing amplifiers, feed into an analog-to-digital converter (ADC). The $\mathrm{ADC}$ is one of the components of the Radiation and Environmental Data Acquisition and Recorder system, model IV (REDAR IV). After conversion, the data are stored in REDAR's memory in one-second groups until they are written on magnetic tape at the end of each four-second period. In addition to the radiation data, the aircraft position, radar altitude, clock time, live time, and meteorological data are recorded on the tape.

The radiation data is analyzed in the field to check the quality of the data and provide feedback for additional flights. There are several methods of data processing which may be employed to view the data. The Gross Count rate (GC) method calculates the exposure rate from all gamma rays detected during each one-second sample. The results are presented as a series of letters along the flight 
path which is superimposed on either a map or photograph of the survey area. With this display, large-scale variations of the radiation field within the whole survey area may be easily seen. However, this display is not as helpful in finding radiation sources of small extent.

A transportation accident involving radioactive materials would most likely involve isotopes which are man-made. These isotopes generally have half-lives much shorter (several years to thousands of years) than the parents of the naturallyoccurring radioisotopic decay chains (billions of years) and emit gamma rays whose energies are limited below about $1400 \mathrm{keV}$. An algorithm (MMGC - manmade gross count) employing this information can search through the radiation spectra and highlight those locations where an excess of the man-made isotopes are found. This algorithm thus suppresses changes in the natural background field and enhances variations due to contributions by man-made isotopes.

\section{Ground-Based Measurements}

In case of a transportation accident involving radioactive material, the aerial radiation system would measure the extent of any release of radioactive material. During the cleanup process, ground-based measurements would be made to check the progress and ensure that all contamination was removed from the area.

The RSL has deployed crews with HPGe detectors on tripods to provide detailed measurements of the isotopic composition and concentrations at contaminated sites. In these surveys, a team of scientists and technicians uses the HPGe detectors to record the gamma-ray energy spectrum at locations on a predefined grid. Since an individual ground-based measurement can be made for a much longer time than an individual aerial measurement, the concentration and location of the identified isotopes can be determined much more precisely. For each aerial survey, a small number of ground-based measurements are performed to check the validity and integrity of the aerial data.

In addition to the in situ gamma-ray measurements, soil samples can be taken at the site and returned for detailed analysis in the laboratory. A radionuclide assay can be tailored to measure the quantity of a specific isotope in the soil sample. Typically, the soil sample assays determine the concentrations of four common isotopes $\left({ }^{137} \mathrm{Cs},{ }^{226} \mathrm{Ra},{ }^{232} \mathrm{Th}\right.$, and $\left.{ }^{40} \mathrm{~K}\right) .{ }^{137} \mathrm{Cs}$ is a radioactive fission product found in trace quantities worldwide as a result of above-ground nuclear weapons tests. The other three isotopes are members of naturally-occurring radioactive decay chains. This measurement has the possibility of being the most precise and of finding the smallest quantity of an isotope in the sample.

The in situ measurements record the radiation emitted from a much smaller area than that from the aerial measurements. In general terms, the aerial radiation 
detectors measure gamma rays emitted from a circle on the ground whose radius is approximately the height of the aircraft. For a helicopter survey, this is usually 150 feet; for a B-200 airplane. survey, this is usually 500 feet. If the ground is relatively flat, the in situ measurements will record gamma rays from a circle with roughly a 30 -foot radius. By contrast, the soil sample measurements remove a quantity of material within a circle of a few inches.

The length of time allotted to measuring the radiation from a spot on the ground determines the accuracy of the measurement. The statistical errors in the measurement decrease as the number of gamma rays collected by the detectors increases. The aircraft is generally moving over the terrain fairly quickly, so the time available for each measurement is quite short (typically a few seconds). The in situ measurements are stationary and generally extend for a few minutes, although they may last for a few hours if the higher accuracy is desired. The soil sample assays usually are several hours in length, but can extend to several days.

The minimum detectable activity increases as the sample size decreases. If the radionuclides are distributed in the soil in a uniform manner over distances of several miles, a few, very accurate soil samples may represent the best measurements which can be made. However, if the distribution is varying significantly over this same area, an extremely large number of these soil samples would need to be made to completely and accurately characterize the distribution. In such cases, a more economical scheme might rely on using the in situ measurements. Even this may prove to be too large an undertaking and an aerial survey may be needed. The trade off depends on the desired accuracy in the results, the size of the survey area, the time available for the measurements, the cost of an extended in situ survey, etc.

\section{General Multispectral Capabilities}

The two multispectral scanners employed by the RSL divide the visible, near infrared, and thermal bands of the spectrum into 11 distinct channels. The Daedalus Model 1260 scanner normally provides 10 channels of visible and near infrared wavelengths (380-1100 nm) and a single thermal channel at 8500-14000 nm. The Model 1268 scanner provides 9 channels of visible and near infrared wavelengths (420-1050 $\mathrm{nm}$ and $1550-1750 \mathrm{~nm})$ and 2 thermal channels (3000-5000 $\mathrm{nm}$ and $8500-14000 \mathrm{~nm})$.

Unlike a photographic camera, the scanners build an image as a series of individual lines perpendicular to the flight path which are collected as the aircraft flies. The scan rate is a function of the aircraft speed and is set so that the scan lines abut each other. While the photographs are collected nearly instantaneously with large delays between each photograph, the scanner is collecting data for its 
image continuously. One - long image is continually built as the aircraft follows a straight-line path. If the aircraft tilts or turns, the geometry of the image is affected, so normal operations involve straight flight paths. If the data to be collected is following a road, the survey mission can be constructed as a sequence of distinct straight-line segments.

The instantaneous field of view of the scanner is 2.5 milliradians, so if the aircraft is flying $\mathbf{5 0 0 0}$ feet above the ground, a 12-foot-diameter object would produce a single pixel in the image. While the spatial resolution of these scanners is not as high as that of film cameras, the scanners possess a much greater spectral selectivity of wavelengths and a greater sensitivity over this band. The approximately $86^{\circ}$ side-to-side field of view means that the scanner records data on the ground about as far to each side of its path as it is above the ground.

Analysis algorithms can be applied to the images to create a temperature for each point in the image. Typically, the algorithms can produce a temperature resolution of $0.1^{\circ} \mathrm{Cfrom}$ the scanner data. From this temperature image, further algorithms may be applied to distinguish dry land from water or water-laden land. Such a technique has been used in the past to locate regions where groundwater is seeping through the soil surface and creating areas where surface contaminations may be transported from one area to another.

Digital processing procedures are also available to analyze the spectral signature of different surface materials. Some materials exhibit a unique spectral signature that can be used to differentiate and identify the materials. Small signal differences can be enhanced and different band combinations used to detect and map various biophysical parameters that are important for environmental assessments.

\section{General Photographic Capabilities}

The human brain is capable of extracting a large amount of information from a seemingly simple photograph. Often a single vertical photograph of an area can present more information to the viewer than many pages of descriptive text or tables of numbers. Aerial photographs taken at the same altitude at different times of the year or in different years can readily show both changes in vegetation patterns or the results of human activities in the area.

Aerial photographs are used extensively as a background for the presentation of the radiation survey data discussed earlier to clearly show what is at the center of a region of elevated radiation. Aerial photographs are also used as crossreferences for the presentation of infrared images, so the points of interest in the infrared image can be related to an object in the visible light spectrum. 
The use of different cameras and lenses at the same altitude can provide different fields of view and resolutions. Various types of film can also produce significantly different. resolutions. The main cameras used by the RSL photographic team are the:

(1) Wild Heerbrugg RC-10 Photogrammetric Aerial Camera capable of taking up to 580 9-inch $\times 9$-inch images from a single film magazine.

(2) Hasselblad 500/ELM Medium-Format Camera capable of taking up to 70 images on $120 \mathrm{~mm}$ film from a single film magazine.

(3) Linhof Aerotechnika Oblique Camera capable of taking up to 125 4-inch $\times 5$ inch images from a single film magazine.

The Wild Heerbrugg RC-10 camera produces large-format images (9-inch $\times$ 9inch) on film, thus retaining high resolution in the final prints. The photographs are often used as base maps for displaying the data from radiation surveys.

Often a system of four Hasselblad cameras is mounted in one aircraft and synchronized to yield identical fields of view. Each camera can be fitted with a different optical filter and film type to change its sensitivity to different wavelengths of radiation. This creates a set of images of the same area, but in different wavelength bands of the spectrum from visible through the near infrared $(400-900 \mathrm{~nm})$. The field of view of this system can be up to 11 miles $(18 \mathrm{~km})$ wide.

\section{Objectives of an Aerial Survey}

The principal reason for performing a radiation survey of the WIPP routes would be to provide a baseline of the radiation environment along the routes before any transporting began. The survey would document the natural background radiation and locate any existing radiation anomalies along the route. The multispectral survey would provide a baseline of the natural environment and locate any environmental anomalies along the route. The photographic survey would document land use and its images would provide useful emergency response information in case of a transportation accident.

The information collected during the survey of the routes would be inspected for general reliability and usefulness, but would not be analyzed in detail. The data would be kept in storage until needed. If a transportation accident occurred, then the data for that area would be analyzed, thus minimizing the cost of the survey. A GIS database would track information needed for an emergency response and provide instant access of location-specific data.

The major deliverables of a survey would include: (1) archives of aerial photographs, radiation data, and multispectral data, maintained at the RSL; (2) 
electronic imagery indexed by route and location; and (3) a GIS data set composed of many data layers which could be combined into presentations as needed or desired.

\section{Results from a Demonstration Survey}

Two flights (multispectral/photographic . and radiation) collected data along portions of the highway between the Las Vegas city limits and the Nevada Test Site. The multispectral/photographic flight employed a Citation aircraft and flew at four separate altitudes over a portion of the highway near Indian Springs.

\section{Photographic Results}

Figures 1-4 show the photographic frames which most closely match the corresponding multispectral scanner image from Figure 5. In each photograph, North is towards the left, and East is towards the top. Figure 1 is a photograph taken at an altitude of 1,000 feet. Parking lot and highway line markings (4-6 inches wide) are clearly visible. Individual desert plants are also easily seen. Figure 2 is a photograph taken at a 2,500-foot altitude. The highway line markings are still visible (although not as easily discernible as at 1,000 feet) since we know where to look for them and they have a distinct shape. If the markings were only as long as they are wide, they would not be recognizable at this altitude.

Figure 3 shows the same area from 5,000 feet above the ground. The highway line markings have nearly disappeared. Sidewalks and cement walkways (2-3 feet wide) in the abandoned housing area in the center of the photograph are becoming harder to see. Figure 4, from 10,000 feet above the ground, gives a wide field of view, but automobiles on the road are just barely visible. Houses and individual trees (if they are located on a light-colored background) are easily discernible in the picture. Highway markings have definitely disappeared. Automobiles (approximately 6 feet by 12 feet in size) are barely recognizable. At the bottom of the figure, the difference in highway color is caused by the recent resurfacing of the pavement.

For the same camera and type of film, both the area covered and the resolution of an aerial photograph depend on the altitude of the aircraft. Table 1 below presents a summary of the coverage and resolution for the aircraft altitudes used in Figures 1-4. The resolution listed in the table more accurately reflects the size of objects which could be seen from the listed altitudes. The object sizes discussed 
in the previous paragraph relied on the object's length being much different from the width.

Table 1. Photographic field of view and resolution at four altitudes as determined from Figures 1-4.

\begin{tabular}{cccc}
\hline \hline Altitude. (feet) & \multicolumn{2}{c}{ Linear field of view (miles) } & Resolution (feet) \\
\hline 1,000 & $\cdots$ & 0.28 & 0.75 \\
2,500 & & 0.71 & 1.5 \\
5,000 & & 1.42 & 3 \\
10,000 & & 2.84 & 6 \\
\hline \hline
\end{tabular}

\section{Multispectral Results}

The multispectral scanner data were collected aboard the Citation aircraft using the Daedalus Model 1268 scanner. The multispectral scanner images for four altitudes are displayed in Figure 5. In this display, each image consists of $300 \mathrm{scan}$ lines. The side-to-side field of view of the images is very close to the field of view of the photographs in Figures 1-4. As discussed earlier, the scanner images are constructed over time as the aircraft tries to follow a straight flight path. Any air turbulence causing the aircraft to tilt or pitch will cause geometric distortions in the scanned image. The line-to-line jitter from air turbulence is very obvious in the bottom of the 10,000-foot altitude image, although it can be seen in all of the images. This jitter can be removed from the images through additional processing.

Vegetation vigor is easily discerned from these images. Red in these images indicates actively-growing vegetation (predominantly trees and grass in these pictures). Asphalt and cement appear as dark gray, while the desert sand is a lighter shade of gray. The dark brown, crushed rock at the entrance to the base and around several of the base buildings appears green in these images, while the track and baseball infield appear as very light shades of green. The lawns around the abandoned housing area just south of the highway appear as a light tan in the multispectral scanner image indicating that the grass is either dead or dormant. The trees in this area are a very pale red, much different from the trees just 
across the road. This correlates with the photographs which.show brown grass and trees with very few leaves.

Figure 6 is another multispectral image taken at 5,000 feet above ground level over a drainage area just west of Cactus Springs, Nevada. The edge of Cactus Springs is just visible at the top of the image as the string of vegetation and cleared dirt area. As with the previous figures, north is to the left in the figure and east is towards the top. Air turbulence is very apparent as the whole length of the road exhibits a very jagged profile.

A great amount of information may be gathered from the image. The principal slope of the land is from right to left with a smaller slope from bottom to top. Rain falling in the mountains flows east and north until it reaches the road in the middle of the image where a drainage ditch temporarily prevents further flow. Enough water is retained at the base of the ditch to allow a line of shrubs to grow. After the water passes under the highway, the slope of the land decreases and the flow pattern spreads out and turns eastward. The white streaks on each side of the image are dirt trails along power line routes.

\section{Nuclear Radiation Results}

The radiation flight consisted of a BO-105 helicopter, equipped with eight 2-inch $\mathrm{x}$ 4-inch x 16-inch NaI(Tl) detectors, flown at 90 knots (105 miles/hour) at both 300 feet and 500 feet above the ground. At this speed, a gamma-ray spectrum is collected approximately every 150 feet. A helicopter was used for this demonstration because the fixed-wing aircraft had not yet been equipped with the GPS antennae. Because the necessary approvals could not be obtained in time for this survey, the helicopter flew over a radiation source $\left(38 \mathrm{mCi}\right.$ of $\left.{ }^{137} \mathrm{Cs}\right)$ on the RSL compound and this source data was inserted into the highway survey data at Indian Springs, Nevada.

Figure 7 shows the gross count radiation data superimposed on the whole route. To display the data on this scale, each letter represents an average of nine seconds of data. Two items are of importance in this figure. First, the presence of the source is not very well defined by this display. Second; the natural background radiation varies from 0-2 $\mu \mathrm{R} / \mathrm{h}$ just outside Las Vegas to 4-6 $\mu \mathrm{R} / \mathrm{h}$ at the western end of the survey.

Figure 8 shows the gross count data collected 300 feet above the ground as the helicopter passed over the radiation source. The source position was simulated just to the right of the " 5 " in the "BM 3135 " text along the highway in the center of the figure. This small variation in the count rate is not an obvious indication of the presence of the source since changes in the natural background caused variations of this same magnitude. 
Therefore, a different algorithm is desired. The Man-Made Gross Count (MMGC) algorithm suppresses all changes in the natural background field and displays only those areas in which gamma-ray energy spectra deviate from the natural background spectral shape. Figure 9 shows this same area after applying the MMGC algorithm. The source location is now very apparent. Figure 10 shows the same area but the helicopter is flying at 500 feet above ground level. Even here the source location is easily discernable since the background variations are suppressed.

\section{Survey Summary and Future Concerns}

The objectives of the demonstration survey were to show the previously described capabilities of the different survey groups as they might appear when employed to collect the three types of data along a highway. Since the two flights (radiation and multispectral/photographic) could not be scheduled simultaneously, they were flown one day apart and a differential GPS base station was fielded at a fortuitous location midway along the flight route.

The reliance on placing a differential GPS base station at various locations (maybe only 40-50 miles apart) along the flight path complicates the survey considerably and adds significantly to the costs. Certain stretches of highways (principally those passing through the mountains) would probably limit our differential capability to only a few miles for each base station location. Then the base station would have to be moved to a new location for the next small stretch of the survey. This would add significantly to the cost of surveying the routes.

The GPS is operated by the Department of Defense (DoD), which we, as consumers, augment with commercially produced hardware to produce the differential correction signal. This differential mode of operation provides us with sufficient accuracy over our typical-size survey regions. In order to perform the survey over the WIPP transportation routes within reasonable amounts of time and money, we will need to use a different system to determine our position.

DOE has requested the use of the P-code (military) version of GPS from DoD. This will provide a positional accuracy which is not quite as good as that with differential correction, but will probably meet the requirements for these surveys without the need for a differential-broadcasting ground-based station. Not relying on the ground-based station will significantly reduce the expense of conducting the survey.

Alternatively, precise GPS corrections are being broadcast on several commercial satellites which can be received by subscribers for a fee. However, this system is currently only available in selected areas of the United States and may not be useful for a survey which must traverse the entire country. 


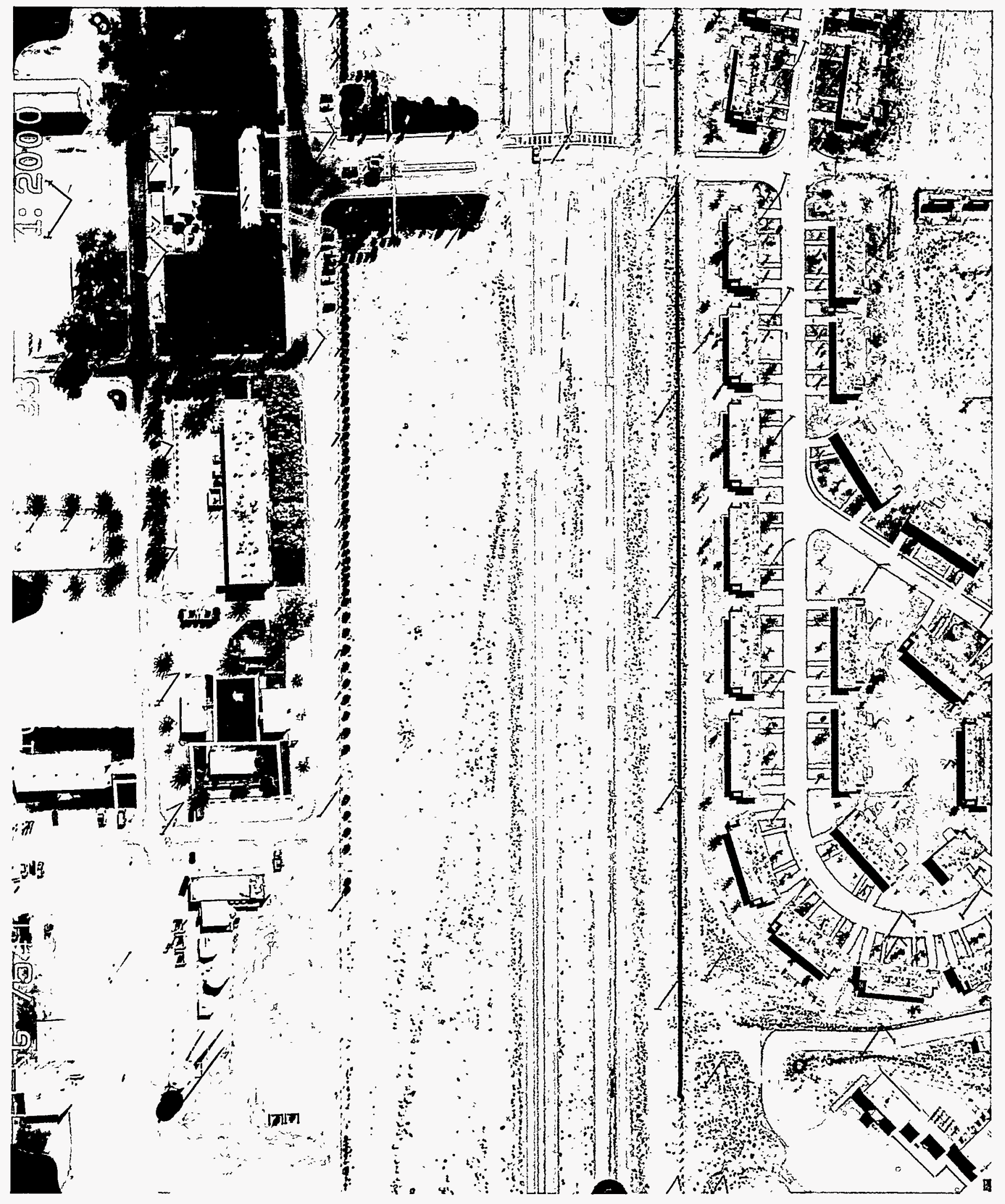

Figure 1. Photographic Image at 1,000-Foot Altitude (Indian Springs, Nevada) 


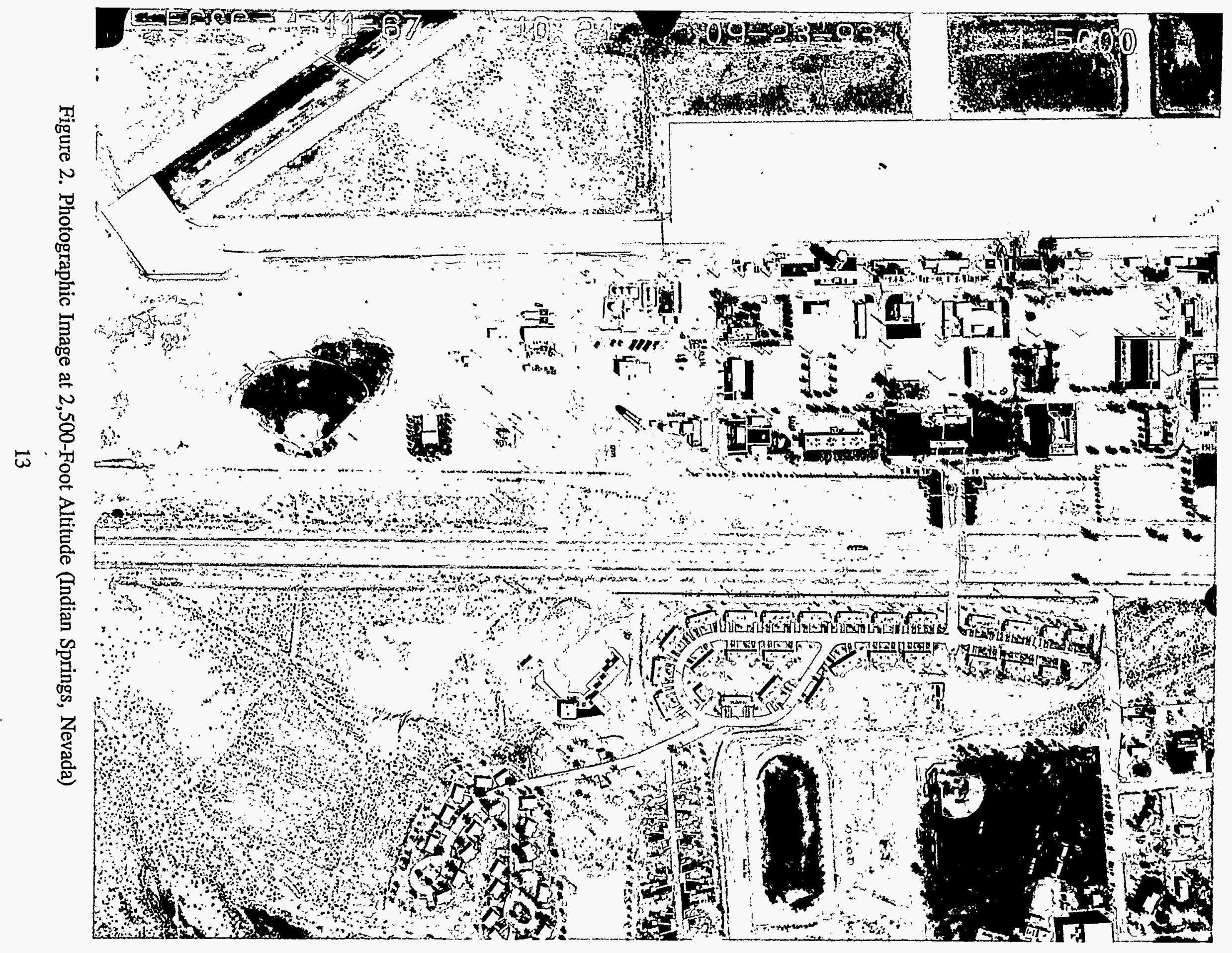




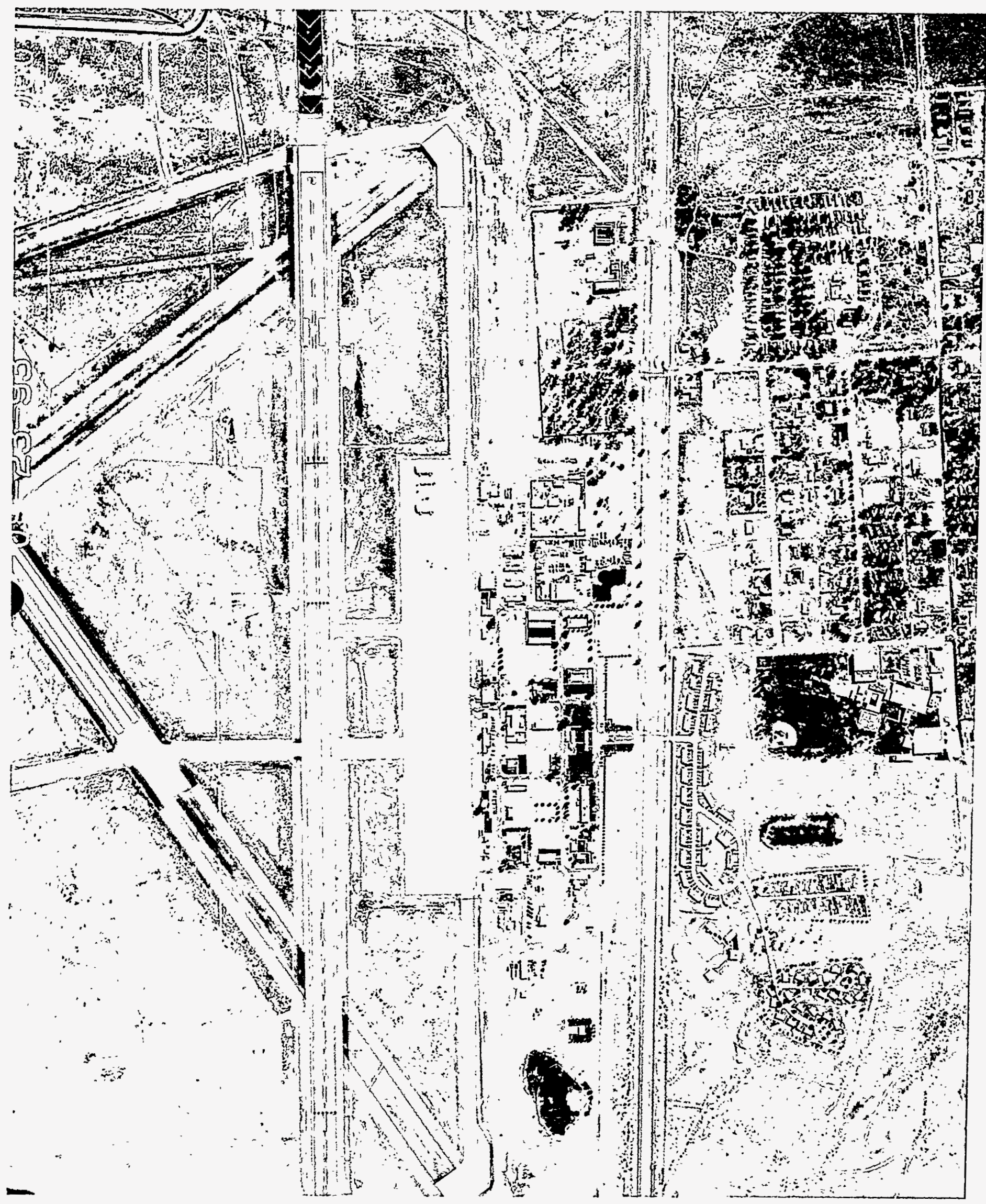

Figure 3. Photographic Image at 5,000-Foot Altitude (Indian Springs, Nevada) 
SI

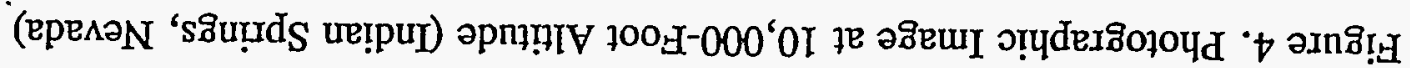

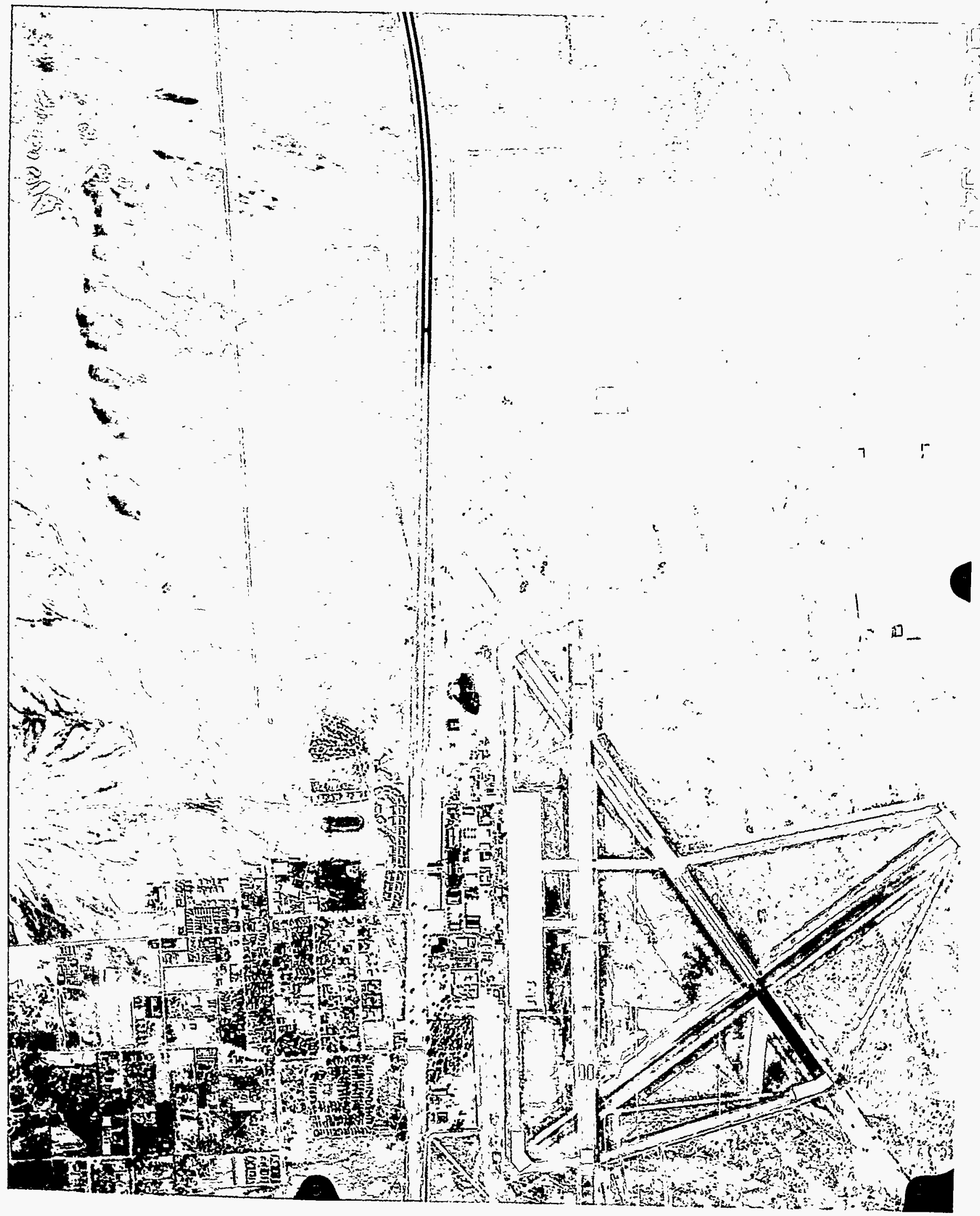



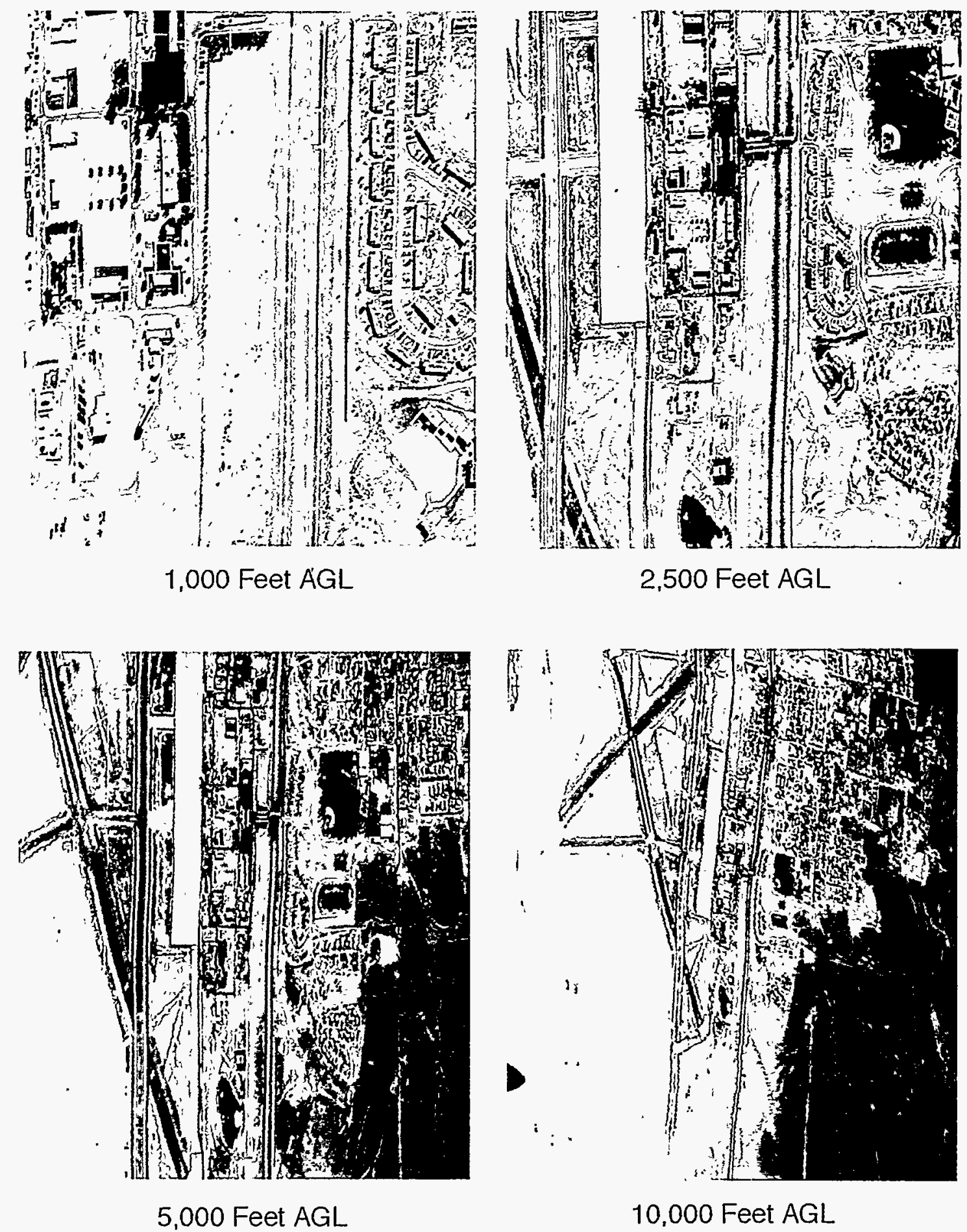

Figure 5. Multispectral Imaging Data at Four Altitudes (Indian Springs, Nevada) 


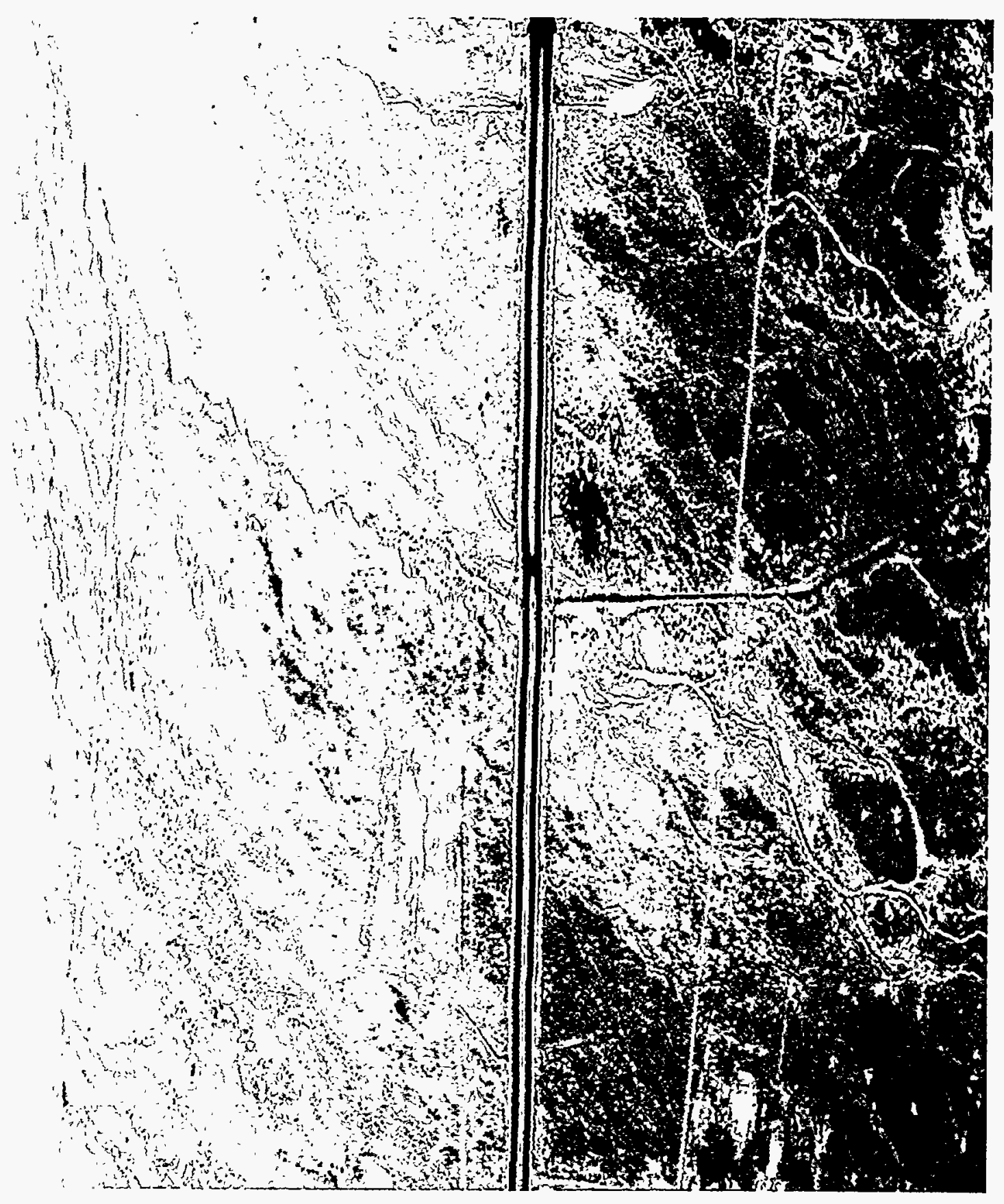

Figure 6. Multispectral Imaging Data at 5,000-Foot Altitude (Drainage Area) 


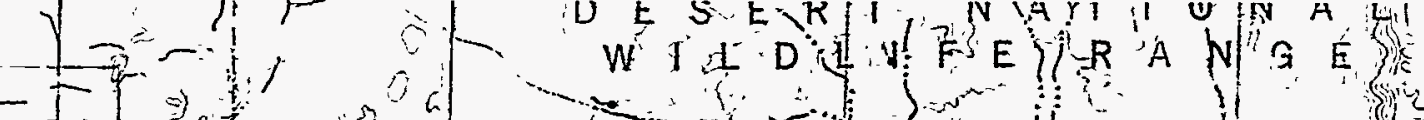

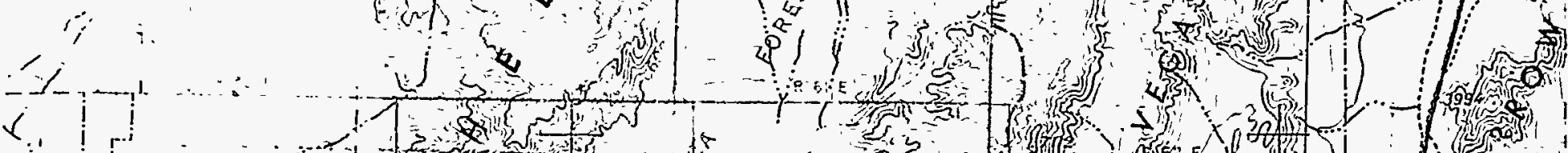
(

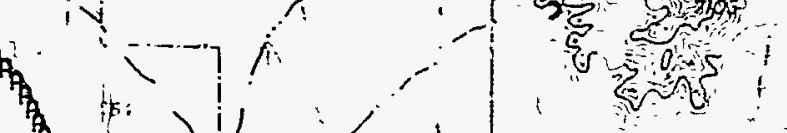

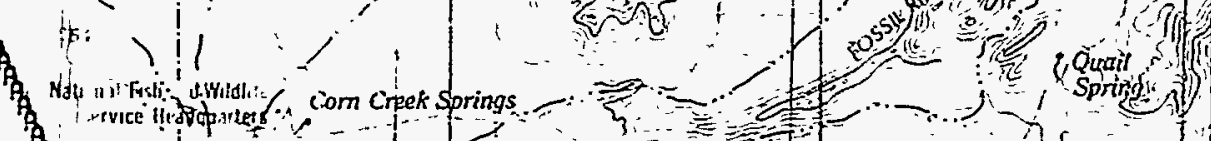
- 量

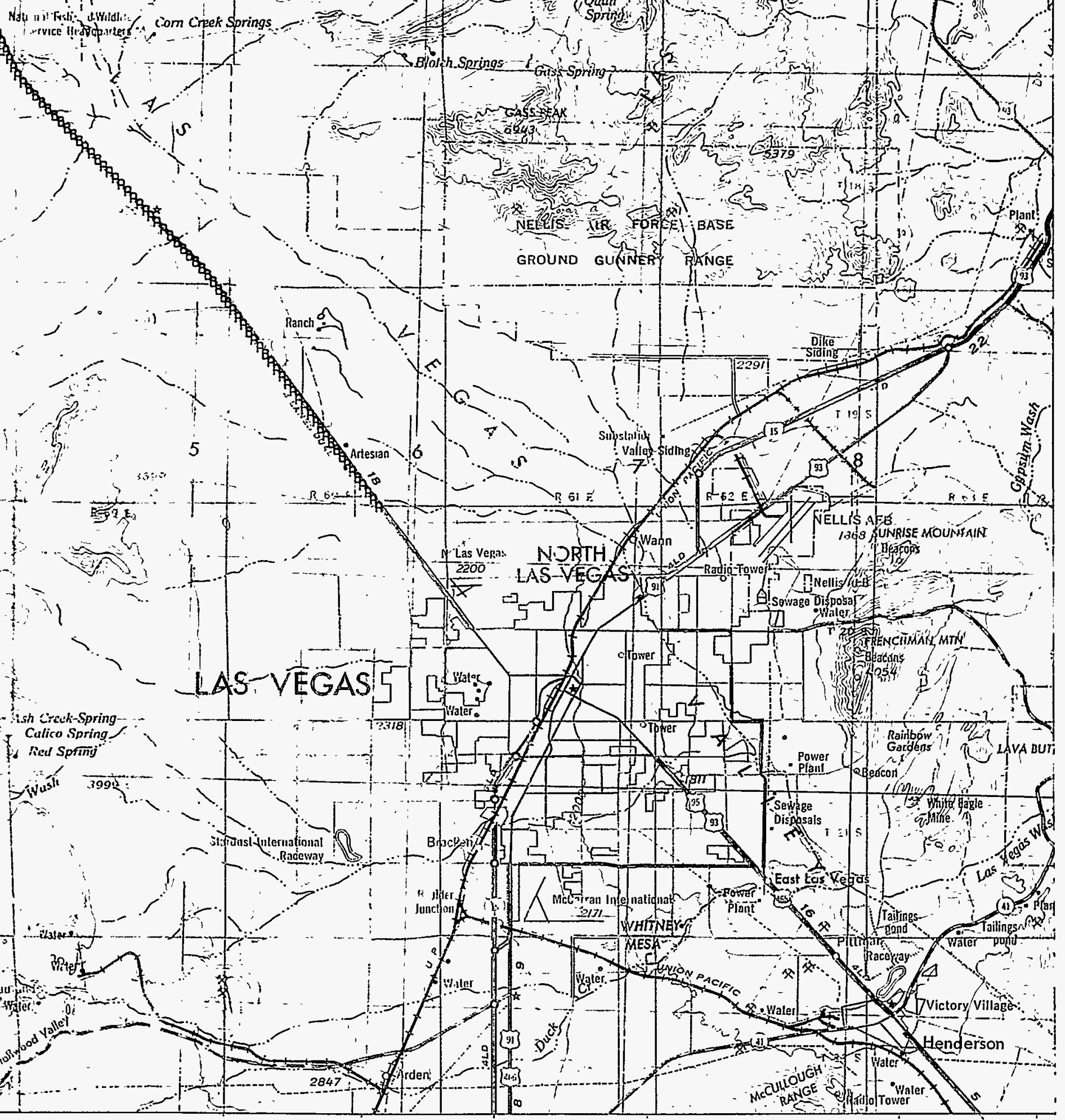




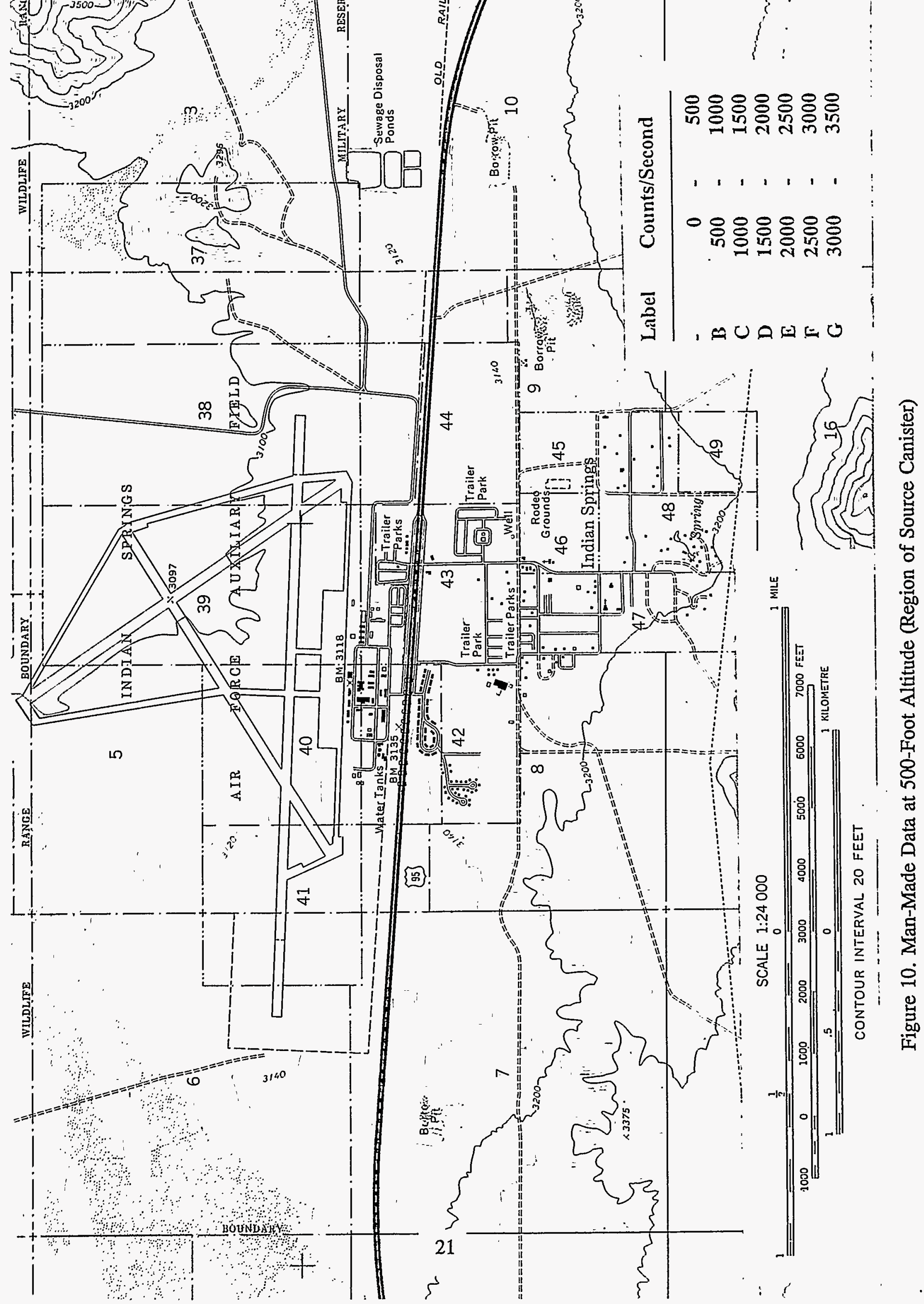




\section{Appendix A \\ Previous Gamma Radiation Surveys}

While the bulk of the RSL's work is the routine aerial survey of DOE facilities and NRC nuclear reactors and uranium processing facilities, it has responded to a long series of radiological incidents and accidents. The highlights of several of the recent responses are discussed here.

Lost ${ }^{60} \mathrm{Co}$ Source. A $325 \mathrm{mCi}{ }^{60} \mathrm{Co}$ source was lost while being shipped from Salt Lake City, Utah to Kansas City, Missouri during June 1968. An RSL fixed-wing aircraft flew the 1100 -mile trip 400 feet above the highway. The source was located (and the presence of ${ }^{60} \mathrm{Co}$ was confirmed) in the aerial data just east of the Missouri River, near St. Joseph, Missouri. The source was recovered by the aircrew shortly after they landed and drove a rental vehicle to the location. ${ }^{4}$

Off-Course Athena Missile. An Athena missile, launched by the U. S. Air Force from Green River, Utah, overshot its target zone in the White Sands Missile Range in New Mexico during July 1970. Radar tracked the missile until it was about 1000 miles south of the United States - Mexico border. Part of the missile's payload was two $470 \mathrm{mCi}{ }^{57} \mathrm{Co}$ sources. When ground crews could not locate the missile during a two-week-long search, an RSL fixed-wing aircraft began flying a grid pattern over the assumed impact area. The aerial search quickly located and identified the sources in a shallow crater. ${ }^{5,6} \mathrm{~A}$ ground survey crew was then able to determine that the two sources did not survive the impact intact and were spread fairly uniformly throughout the impact crater.

Project HAVE SINEW-1. For a test of whether satellite payloads could withstand reentry into the atmosphere, an Athena missile dropped six payloads, carrying nine radioactive sources, on the White Sands Missile Range in August 1971. The RSL's participation in the exercise was to quickly locate the radioactive sources from the air and direct ground crews in the recovery of the payloads: The nine sources were various shapes of the gamma emitter ${ }^{182} \mathrm{Ta}$ - one $100 \mathrm{mCi}$ source and eight $50 \mathrm{mCi}$ sources. The aircraft flew parallel flight lines 600 feet apart and 500 feet above ground over an area of approximately 10 miles by 25 miles. Five of the nine sources were found intact with the rest of their payloads. Two of the other four $50 \mathrm{mCi}$ sources were located away from their payloads. The two sources which were never found were assumed ${ }^{7}$ to have been separated from their payload uprange (outside) of the search area. This exercise demonstrated that the aerial detection system could be used to search for (even small) lost radiation sources.

Mid-Pacific Islands Cleanup Program. A combined aerial and in situ survey ${ }^{8}$ was conducted in the Northern Marshall Islands in 1978. This survey mapped the 
fallout-generated contaminated areas from atmospheric nuclear tests conducted at the Enewetak and Bikini Atolls in the 1950s.

From 1977 through 1979, the RSL assisted the Defense Nuclear Agency in its Enewetak Atoll cleanup project. ${ }^{9}$ The major radioactive contaminant was ${ }^{241} \mathrm{Am}$, which is a decay product of the plutonium in the warheads being tested during the atmospheric tests in the South Pacific. Since this had been the location for several nuclear tests, fission products and soil activation products figured in the analysis of the data.

A set of in situ surveys ${ }^{10}$ conducted on Johnston Atoll in 1980 assisted in defining several regions of transuranic contamination which resulted from three aborted THOR missile tests during the atmospheric nuclear testing series in 1962. This survey mapped the presence of ${ }^{241} \mathrm{Am}$.

Bomarc Missile Site. A fire in a missile bunker in 1960 dispersed weapons grade plutonium around the site. In November 1973, the RSL conducted a survey ${ }^{11}$ over the deactivated missile site. A helicopter, equipped with 405 -inch-diameter x 2inch-thick NaI detectors, flew survey lines 100 feet apart at a 75 -foot altitude. The low altitude was necessary to increase the sensitivity to the low energy gamma rays emitted by ${ }^{241} \mathrm{Am}$ (a decay product of plutonium). The observed ${ }^{241} \mathrm{Am}$ deposition provided a map of where the plutonium had been dispersed.

Cosmos 954 Satellite. In January 1978, the Soviet satellite Cosmos 954 fell back into the atmosphere, broke apart, and fell over a wide region of the Northwest Territories of Canada. ${ }^{12}$ The satellite was powered by a nuclear reactor and scattered radioactive materials over an area of more than 20,000 square miles. Detector arrays were placed in C-130 aircraft and flown at a 750-foot altitude to locate regions of increased radioactivity for further inspection and recovery by ground teams. Since many pieces of radioactive debris were recovered (and no large, single piece of the reactor), the search team concluded that the reactor core had disintegrated during reentry.

Three Mile Island. In late March 1979, one of the reactors at the Three Mile Island (TMI) nuclear power plant suffered a major coolant accident. Helicopters and airplanes from the RSL flew 167 flights in the three months following the accident to determine the direction of the plume of radioactive gases, to identify the isotopes present, and to measure the maximum radiation levels within the plume. The predominant radionuclides seen in the plume ${ }^{13}$ shortly after the accident were ${ }^{88} \mathrm{Kr}$ and ${ }^{88} \mathrm{Rb},{ }^{133} \mathrm{Xe},{ }^{133 \mathrm{~m}} \mathrm{Xe}$, and ${ }^{135} \mathrm{Xe}$. Almost no radioactive particulate matter was present in the measurements. In October 1982, an aerial survey ${ }^{14}$ covered an approximately 50-square-mile area around the plant. With the exception of the area directly over the TMI facilities, the 1982 survey's aerial and 
ground measurements agreed with those obtained in a 1976 survey $^{15}$ of a considerably larger area.

Neutron Logging Source. In Venezuela, in March 1982, an oil well logging company lost an americium-beryllium source with a neutron yield of $4 \times 10^{7}$ neutrons per second. After searching extensively for six weeks by vehicle and by foot and finding nothing, the RSL was asked to assist in the search with its aerial detection equipment. The RSL mounted several sets of ${ }^{3} \mathrm{He}$ proportional counter detectors in a Venezuelan helicopter and began an aerial search. Although calculations indicated that the source should have been easily detectable from the air, it was never located. Speculation finally settled on the scenario that the source had probably been stolen and removed from the area, either for profit or to embarrass the oil well logging company.

${ }^{60} \mathrm{Co}$ Dispersal in Mexico. In November 1983 , a ${ }^{60} \mathrm{Co}$ teletherapy machine was disassembled for scrap steel in Ciudad Juarez, Chihuahua, Mexico. The $450 \mathrm{Ci}$ source capsule, which contained 6000-7000 small pellets, was ruptured. Individual pellets were found at the disassembly site, in vehicles which transported the material, and along the roads to foundaries in Juarez and Chihuahua. An estimated 218-curie quantity of ${ }^{60} \mathrm{Co}$ was melted into 7000 tons of steel products. Contaminated steel products reached buyers in northern Mexico and the United States before the RSL began a survey of the areas over El Paso, Texas; Anapra, New Mexico; and the cities of Ciudad Juarez and Chihuahua, Mexico. Both sides of the highway between Ciudad Juarez and Chihuahua were also surveyed. All of the pellets detected through the various searches were recovered. Most of the contaminated steel products were returned to Mexico and buried. The nature of the source dispersal and its wide dispersion in the environment prohibited a complete recovery of the material.

Reading Prong Formation, Pennsylvania. Pennsylvania's Department of Environmental Resources requested the RSL's help in locating regions of elevated radon gas emissions from the ground. This request followed the discovery ${ }^{16}$ in December 1984 of excessive levels of radon gas in a house in Boyertown, Pennsylvania. The aerial survey provided the Pennsylvania department with contour maps showing which regions possessed high levels of natural background activity. Known geological faults coincided with elevated radon activity. Other regions of elevated activity were suspected to correspond to areas possessing unknown faults or containing uranium-bearing rocks unusually close to the surface.

South Houston, Texas. During May and June 1985, the RSL conducted a survey of many sites in and around South Houston, Texas. These sites had been contaminated during the 1950 s and 1960 s through careless dumping of trash and product residues by the Hastings Pharmaceutical Company. The company 
manufactured technetium and radium sources for medical use, ${ }^{137} \mathrm{Cs}$ sources for well logging, and other radiochemical products.

The Texas Department of Health Resources found cesium, cobalt and radium contamination at some sites and asked the DOE for assistance in locating other possible sites. The helicopter flew a grid pattern at 150 feet above the ground over a 200-square-mile area. In addition to five sites already known, the survey located six other sites contaminated with ${ }^{137} \mathrm{Cs}$, three sites contaminated with ${ }^{226} \mathrm{Ra}$, one site with ${ }^{60} \mathrm{Co}$, and three sites with ${ }^{192} \mathrm{Ir}$. In addition, 37 other locations contained ${ }^{137} \mathrm{Cs}$ activity near the minimum detectable level of the detectors. Using the survey maps, the Texas Department of Health Resources sent ground survey personnel to investigate these additional sites.

Bessemer, Alabama.' On July 2, 1985, the Alabama Department of Public Health requested RSL assistance in locating three ${ }^{137} \mathrm{Cs}$ sources which had disappeared from the Uniroyal Tire and Rubber Company. The sources had been used as gauging sources on a tire production assembly line in Opelika, Alabama until the production line was shut down. Two of the sources were $50 \mathrm{mCi}$ and one was 10 mCi.

An RSL helicopter flew over seven sites identified as possible locations by the Department of Public Health. One of the possible sites, the U.S. Pipe and Foundry Company in Bessemer, showed the presence of ${ }^{137} \mathrm{Cs}$. It was theorized that the sources were dumped into a hopper with scrap steel and smelted to produce steel pipe. The sources were apparently volatilized and radioactive vapor or small particles went up the smoke stack. The radioactive material was trapped in a bag house at the end of the stack and later dumped onto an area approximately 250 feet by 60 feet.

Sequoyah Fuels Uranium Hexaflouride Accident. A tank containing more than 14 tons of $\mathrm{UF}_{6}$ exploded at the Sequoyah Fuels Corporation facility in Gore, Oklahoma in January 1986. The NRC requested both aerial and in situ measurements from the RSL in assessing the impact of the accident. The in situ measurements started less than 36 hours after the accident and provided the NRC with data within hours of collection. The aerial survey covered a 5-mile by 5-mile area surrounding the facility and provided the NRC with radiological contour maps on the eighth day after the accident. RSL personnel also collected high- and intermediate-altitude photographic imagery in both the visible and infrared spectral regions.

Lake Charles, Louisiana. A $1.5 \mathrm{Ci}^{137} \mathrm{Cs}$ source was lost near Lake Charles, Louisiana in late December 1987. The DOE requested both aerial and ground assistance from the RSL in the search for this source. The source was not found in the region of the aerial and ground surveys. The surveys concentrated on the area 
in and around Lake Charles, even though the source container had been shipped to and returned from an offshore oil rig (although apparently without the source being used on the rig).

Nevada Test Site Radioactive Cloud Tracking. Beginning in the 1950 s and continuing until the atmospheric test ban treaty in 1963, originally the military and later the RSL tracked the radioactive clouds from above-ground nuclear tests to determine the extent of the radioactive fallout from each test. After 1963, the RSL continued to provide cloud tracking services with each underground test in anticipation that some gases might be vented from the tests. ${ }^{17}$ In addition, dozens of aerial surveys have mapped the fallout patterns in and around the Nevada Test Site.

In addition to the above responses, the RSL is an integral part of the Federal Radiological Emergency Response Plan (FRERP). In the event of a significant radiological emergency, a Federal Radiological Monitoring and Assessment Center (FRMAC) is established ${ }^{18}$ close to the accident site and the FRMAC provides technical federal assistance to the monitoring and assessment activities. $\mathrm{EG} \& \mathrm{G} / \mathrm{EM}$ recently issued a report ${ }^{19}$ presenting an overview of the FRMAC operations

More than 50 FUSRAP and UMTRAP sites have also been surveyed over the past several decades. These formerly used sites for the production or disposal of nuclear materials and uranium mill tailings sites were surveyed as part of a remedial action program of the DOE. In addition, about a dozen sites have been surveyed at the request of the Environmental Protection Agency or the U.S. Geological Survey. 


\section{Appendix B \\ Previous Multispectral Surveys}

While the bulk of the RSL's multispectral work is the routine aerial survey of DOE facilities, it has responded to a long series of incidents and accidents. The highlights of several of the recent responses are discussed here.

Environmental Monitoring. A survey ${ }^{20}$ over the Salton Sea area of Southern California indicated that land surrounding a new geothermal test area suffered crop damage shortly after the test operations began.

A known Geothermal Resource Area near Steamboat Hills, Nevada was surveyed $^{21}$ in August 1980 to compare the thermal infrared imagery from the Daedalus scanner with previously collected data. The survey collected multispectral scanner data and both visible and infrared film images.

In September 1978, the RSL responded to a DOE request to detect and monitor any damage to the vegetation surrounding the Strategic Petroleum Reserve Site fire near West Hackberry, Louisiana. Two surveys ${ }^{22}$ of this area, one survey in October 1978 immediately after the fire and a follow-up survey in July 1979, collected Daedalus scanner data and both visible and infrared film images. The data indicated regions of vegetation which had been damaged by the fire's smoke plume.

Mount Saint Helens. The RSL conducted a sequence of thermal surveys, two shortly before and one a few months after the eruption, at Mount Saint Helens in Washington. As a result of the data collected on these flights, a series of surveys ${ }^{23}$ was undertaken to map a total of fourteen sites in the Cascade Mountain range.

Rocky Flats Plant Site. As water migrates through the ground, it may encounter a layer of less permeable rock and begin to travel along this layer of rock until it can again proceed downward. If the less permeable . rock layer intersects a hillside, the water may "seep" out of the ground and flow along the surface again. These regions are characterized by saturated soil or standing water and can be easily detected from the air by the differences in their thermal patterns. A survey ${ }^{24}$ of the DOE Rocky Flats Plant in 1989 used the multispectral scanner to detect and map regions around the plant where water was seeping through the ground. The survey located seeps forming adjacent to fields used in the treatment of sewage generated at the plant. The survey was requested to determine if these seeps allowed water to bypass the network of holding reservoirs and to enter the streams which drain the area.

Savannah River Site. The most extensive multispectral surveying has been conducted at the Savannah River Site (SRS) near Aiken, South Carolina. Initially, 
the surveys were intended to measure the effects on the streams and ponds of the SRS of higher temperature water released from the various nuclear reactors.

Several surveys ${ }^{25}$ mapped the changes in the surface water isotherms in Par Pond and the Savannah River as a function of time of year. Another survey ${ }^{26}$ measured the changes in the surface water isotherms in L Lake as a function of time of day while the L Reactor was operating. Vegetation type, amounts, and condition have been mapped for several SRS locations of special environmental interest.

Three Mile Island. In late March 1979, one of the reactors at the Three Mile Island (TMI) nuclear power plant suffered a major coolant accident. Two thermal infrared scanning flights were conducted ${ }^{27}$ shortly after the accident to obtain baseline information on the thermal characteristics of the plant and river in case problems with the reactor required future surveys.

Liquified Natural Gas Spills. Throughout 1980 and 1981, the RSL participated in a series of liquified natural gas spill tests conducted at China Lake Naval Weapons Center in California. The multispectral scanner collected data to assess the impact which the spilled liquified gas had on the plant life.

Brookhaven National Laboratory. In May-June 1990, the RSL conducted a multispectral scanner survey ${ }^{28}$ at the Brookhaven National Laboratory (BNL). The purpose of the survey was to show how new techniques in analyzing the multispectral data could benefit the environmental management of the BNL. Three separate techniques were applied to data taken over the former landfill site to emphasize the strengths of each process. 


\section{Appendix C \\ Previous Photographic Responses}

Since much of the RSL's photographic work supports the other two programs, little is usually written about their work. Instead, some small subset of the photographs is used as a base map for the radiation data or as an orientation for the multispectral data in one of their reports. In addition to the photographic work supporting these other two programs, photographs are taken of all DOE facilities on a regular basis to document changes in the land use in and around the facility.

Three Mile Island. In late March 1979, one of the reactors at the Three Mile Island (TMI) nuclear power plant suffered a major coolant accident. A large format aerial mapping camera photographed ${ }^{29}$ an area of approximately $25 \times 40$ miles. The mapping images were collected at 4,000-, 10,000-, and 20,000-foot altitudes. A four-camera system assisted with the multispectral survey at an 8,000 foot altitude. In addition, five flights collected oblique aerial photographs of the area from helicopter platforms. 
Appendix D

List of the Elements

Ac Actinium

$\mathrm{Ag}$ Silver

Al Aluminum

Am Americium

Ar Argon

As Arsenic

At Astatine

$\mathrm{Au}$ Gold

B Boron

$\mathrm{Ba}$ Barium

Be Beryllium

$\mathrm{Bi}$ Bismuth

Bk Berkelium

$\mathrm{Br}$ Bromine

C Carbon

$\mathrm{Ca}$ Calcium

$\mathrm{Cd}$ Cadmium

$\mathrm{Ce}$ Cerium

Cf Californium

$\mathrm{Cl}$ Chlorine .

$\mathrm{Cm}$ Curium

Co Cobalt

$\mathrm{Cr}$ Chromium

Cs Cesium

$\mathrm{Cu}$ Copper

Dy Dysprosium

Er Erbium

Es Einsteinium

$\mathrm{Eu}$ Europium

F Fluorine

$\mathrm{Fe}$ Iron

Fm Fermium

Fr Francium

$\mathrm{Ga}$ Gallium

Gd Gadolinium
Ge Germanium

$\mathrm{H}$ Hydrogen

He Helium

Hg Mercury

Hf Hafnium

Ho Holmium

In Indium

I Iodine

Ir Iridium

K Potassium

Kr Krypton

La Lanthanum.

$\mathrm{Li} \quad$ Lithium

Lr Lawrencium

$\mathrm{Lu}$ Lutetium

Md Mendelevium

Mg Magnesium

Mn Manganese

Mo Molybdenum

N Nitrogen

$\mathrm{Na}$ Sodium

$\mathrm{Nb}$ Niobium

Nd Neodymium

$\mathrm{Ne}$ Neon

$\mathrm{Ni}$ Nickel

No Nobelium

$\mathrm{Np}$ Neptunium

$\mathrm{O}$ Oxygen

Os Osmium

P Phosphorus

$\mathrm{Pa}$ Protoactinium

$\mathrm{Pb}$ Lead

Pd Palladium

$\mathrm{Pm}$ Promethium

Po Polonium
Pr. Praeseodymium

Pt Platinum

$\mathrm{Pu}$. Plutonium

$\mathrm{Ra}$ Radium

$\mathrm{Rb}$ Rubidium

Re Rhenium

$\mathrm{Rh}$ Rhodium

Rn Radon

$\mathrm{Ru}$ Ruthenium

$S$ Sulfur

$\mathrm{Sb}$. Antimony

Sc Scandium

Se Selenium

$\mathrm{Si}$ Silicon

Sm Samarium

Sn Tin

Sr Strontium

Ta Tantalum

$\mathrm{Tb}$ Terbium

Tc Technetium

$\mathrm{Te}$ Tellurium

Th Thorium

Ti Titanium

T1. Thallium

Tm Thulium

U. Uranium

V Vanadium

W Tungsten

Xe Xenon

$Y$ Yttrium

$\mathrm{Yb}$ Ytterbium

Zn Zinc

$\mathrm{Zr}$ Zirconium 


\section{Acknowledgements}

Both Joel Jobst and Harvey Clark must be thanked for the description of the radiological detection system and their help in assembling much of the historical radiation survey response material.. In addition, discussions of the multispectral survey capabilities with Larry Tinney, Dave Hawley, Jan Shines, and Tim McCreary were very helpful. I am thankful to Kirk Knighten and Marc Rivera for extensive discussions of the photographic capabilities described in this report. 


\section{References}

1. F. J. Davis and P. W. Reinhardt, "Instrumentation in Aircraft for Radiation Measurements," Nucl. Sci. Eng., 2, 713-727, 1957.

2. J. E. Jobst, "The Aerial Measuring Systems Program," Nuclear Safety, 20, 136-147, March/April 1979.

3. J. E. Jobst, Recent Advances in Airborne Radiometric Technology, Report RSL8403, EG\&G/EM, Las Vegas, Nevada, February 1984.

4. V. F. Weissman and J. E. Hand, ARMS Aircraft Recovery of Lost Cobalt-60 Source, Report EGG-1183-1395, EG\&G/EM, Las Vegas, Nevada, July 1968.

5. J. F. Doyle and Z. G. Burson, Locating the Lost Athena Rocket in Mexico by ARMS and Subsequent Soil Analysis, Report EGG-1183-1508, EG\&G/EM, Las Vegas, Nevada, February 1971.

6. L. J. Deal, J. F. Doyle, Z. G. Burson, and P. K. Boyns, "Locating the Lost Athena Missile in Mexico by the Aerial Radiological Measuring System (ARMS), " Health Physics, 23, 95-98, July 1972.

7. HAVE SINEW-1 Recovery Operation, Report EGG-1183-1578, EG\&G/EM, Las Vegas, Nevada, March 1973.

8. W. J. Tipton and R. A. Meibaum, An Aerial Radiological and Photographic Survey of Eleven Atolls and Two Islands within the Northern Marshall Islands, Dates of Surveys: July-November 1978, Report EGG-1183-1758, EG\&G/EM, Las Vegas, Nevada, June 1981. This work is also included in a larger report: USAEC, Enewetak Radiological Survey, Report NVO-140, 3 volumes, Las Vegas, Nevada, USAEC Nevada Operations Office, October 1973.

9. W. J. Tipton, A. E. Fritzsche, R. J. Jaffe, and A. E. Villaire, An In Situ Determination of ${ }^{241}$ Am on Enewetak Atoll, Date of Survey: July 1977 to December 1979, Report EGG-1183-1778, EG\&G/EM, Làs Vegas, Nevada, . November 1981.

10. R. J. Jaffe and W. J. Tipton, A Radiological Survey of Johnston Atoll, Dates of Survey: April-August 1980, Report DNA-8114 First Revision, EG\&G/EM, Las - Vegas, Nevada, April 1982.

11. Radiological Survey of the McGuire Bomarc Site, New Jersey, Date of Survey: November, 1973, Report EGG-1183-1624, EG\&G/EM, Las Vegas, Nevada, March 1974. 
12. Operation Morning Light, A Non-Technical Summary of U.S. Participation, DOE Report NV-198, DOE/NV, Las Vegas, September 1978. A classified report also exists: Morning Light Technical Report, DOE Report NV-223, DOE/NV, Las Vegas, March 1981.

13. R. H. Beers, Z. G. Burson, T. C. Maguire, and G. R. Shipman, Airborne Cloud Tracking Measurements During the Three Mile Island Nuclear Station Accident, Date of Survey: March-June 1979, Report EGG-10282-1009, EG\&G/EM, Las Vegas, Nevada, December 1984.

14. D. P. Colton, An Aerial Radiological Survey of the Three Mile Island Nuclear Station and Surrounding Area, Date of Survey: October 1982, Report EGG-102821021, EG\&G/EM, Las Vegas, Nevada, August 1983.

15. A. E. Fritzsche, An Aerial Radiological Survey of the Three Mile Island Station Nuclear Power Plant, Date of Survey: August 1976, Report EGG-1183-1710, EG\&G/EM, Las Vegas, Nevada, March 1977.

16. R. A. Hoover and D. E. Mateik, "Aerial Survey Efforts in the Search for Radon Contaminated Houses in the Reading Prong Area Near Boyertown, PA," Proceedings of the Topical Meeting on Radiological Accidents - Perspectives and Emergency Planning, American Nuclear Society, Bethesda, Maryland, September 15-17, 1986, CONF-860932, March 1987, pp. 43-46.

17. Z. G. Burson, A Review of Aerial Radiological Surveys of Nevada Test Site Fallout Fields 1951 through 1970, Report NVO-314, DOE/NV, Las Vègas, Nevada, December 1987.

18. J. F. Doyle, "Role of the FRMAC Following an Accident," Proceedings of the Topical Meeting on Radiological Accidents - Perspectives and Emergency Planning, American Nuclear Society, Bethesda, Maryland, September 15-17,1986, CONF-860932, March 1987, pp. 287-289.

19. Federal Radiological Monitoring and Assessment Center (FRMAC), Overview of FRMAC Operations, Report NV-358, DOE/NV, Las Vegas, Nevada, September 1992.

20. Imperial Valley Environmental Project Quarterly Data Report (Draft), Chapter 7: Catalogue of Airborne Remotely Sensed Data, EG\&G, Inc., Las Vegas, Nevada, April 1977.

21. E. L. Doak, An Aerial Thermal Survey of Steamboat Hills, Nevada, Date of Survey: 15 August 1980, Report EGG-1183-1774, EG\&G/EM, Las Vegas, Nevada, January 1981. 
22. I. W. Ginsberg, D. L. Hawley, and S. A. Levy, Environmental Effects of the Hackberry Fire Strategic Petroleum Reserve, West Hackberry, Louisiana, Date of Surveys: September-October 1978 and July 1979, Report EGG-1183-1767, EG\&G/EM, Las Vegas, Nevada, January 1981.

23. D. L. Hawley and S. B. Brewster, Jr., A Thermal Infrared Survey of Selected Sites in the Cascade Mountain Range of California, Oregon, and Washington, Date of Survey: July 1981, Report MRSD-8207, EG\&G/EM, Las Vegas, Nevada, July 1982.

24. R. G. Best, S. B. Brewster, Jr., E. L. Doak, and J. E. Shines, A Multispectral Scanner Survey of the. United States Department of Energy's Rocky Flats Plant, Golden, Colorado, Survey Date: June-July 1989, Report MRSD-8902, EG\&G/EM, Las Vegas, Nevada, September 1989.

25. D. S. Negri and J. E. Shines, Thermal Infrared Surveys of the Savannah River Plant. Date of Surveys: April, May, and September 1984, Report DOE(ONSSRL)-8601, EG\&G/EM, Las Vegas, Nevada, March 1986.

26. D. S. Negri, Thermal Infrared Survey of the Savannah River Plant, Survey Date: April 1986, Report DOE(ONS-SRL)-8705, EG\&G/EM, Las Vegas, Nevada, April 1987.

27. R. H. Beers, Z. G. Burson, T. C. Maguire, and G. R. Shipman, Airborne Cloud Tracking Measurements During the Three Mile Island Nuclear Station Accident, Date of Survey: March-June 1979, Report EGG-10282-1009, EG\&G/EM, Las Vegas, Nevada, December 1984.

28. R. G. Best, D. W. Brickey, S. B. Brewster, Jr., and J. E. Shines, A Multispectral Scanner Survey of the United States Department of Energy's Brookhaven National Laboratory, Long Island, New York, Survey Date: May-June 1990, Report MRSD-9001, EG\&G/EM, Las Vegas, Nevada, July 1990.

29. R. H. Beers, Z. G. Burson, T. C. Maguire, and G. R. Shipman, Airborne Cloud Tracking Measurements During the Three Mile Island Nuclear Station Accident. Date of Survey: March-June 1979, Report .EGG-10282-1009, EG\&G/EM, Las Vegas, Nevada, December 1984. 
DOE/DP

L. E. Gordon-Hagerty

O. W. Taylor

(1)

(1)

DOE/HQ

OSTI.

(2)

\section{EG\&G/EM}

J. F. Doyle LVAO (1)

S. R. Riedhauser LVAO

G. R. Shipman WAMO (1)

W. J. Tipton LVAO

(1)

P. H. Zavaittaro LVAO

Central Files

\section{LIBRARIES}

(1)

M. R. Dockter

S. C. Ronshaugen

Public Reading Room

TIO

(10)

(1)

RSL

TIC

WAMO

(20)

(1)

(1)

CAPABILITIES OF THE

DOE REMOTE SENSING LABORATORY'S

AERIAL MEASURING SYSTEM

EGG 11265-1116.

DATE OF REPORT: SEPTEMBER 1995 